\title{
Elfriede Jelinek: un Premio Nobel para la literatura austriaca
}

\author{
Herwig WEBER \\ Universidad Nacional Autónoma de México
}

En relación con el Premio Nobel de Literatura siempre se habla de sorpresas. J. M. Coetzee fue una sorpresa (autor blanco de África del Sur), Imre Kértesz (húngaro, antes del premio prácticamente desconocido), una sorpresa más grande fueron V. S. Naipaul (un escritor de best seller) y sobre todo Gao Xingiian (al menos para el mundo occidental), hasta Günter Grass (el premio venía décadas demasiado tarde). Y por supuesto también Elfriede Jelinek --mujer austriaca, feminista, intelectual de izquierda, algunos años miembro del partido comunista, crítica del gobierno conservador-derechista de Austria y de la sociedad patriarcal en Europa - fue una sorpresa. Los comentaristas en los periódicos esperaban otros autores y otros autores esperaban el premio -los grandes viejos de la literatura estadounidense Philip Roth y John Updike, el gran viejo de la literatura latinoamericana Mario Vargas Llosa y, entre las mujeres, Margaret Atwood, Joyce Carol Oates o Doris Lessing.

Pero de todas formas no falta la lógica de la decisión en Estocolmo, pues tal vez no hay otra autora en la actualidad que refleje tanto como Elfriede Jelinek las diferentes corrientes literarias y la tradición occidental que al mismo tiempo critica.

Elfriede Jelinek nació en 1946 en Stíria en el sur de Austria y representa a la generación literaria austriaca de posguerra como ninguna otra autora. En los años sesentas y setentas tiene una conexión muy estrecha con el grupo literario más importante en Austria, con la Wiener Gruppe (grupo vienés). Los miembros del grupo vienés como H. C. Artmann, Gerhard Rühm, Oswald Wiener o Friedrich Achleitner escribieron literatura experimental que quiso quebrar las reglas de la producción literaria antes de la Segunda Guerra Mundial. Dentro de esta misma corriente se encuentra el primer texto en prosa publicado de Jelinek Somos anzuelos, baby (Jelinek, 1970). En este texto podemos ver cierta influencia de la literatura pop de Estados Unidos - Jelinek experimenta con la lengua trivial y pone en escena estrellas de los años sesentas como Ed Sanders, Frank Zappa, los Beatles, King Kong y Batman. 
En una colección de textos editada por Peter Handke, Jelinek publicó su primer cuento de vampiros - iel extranjero! perturbadores del silencio en una noche de verano del silencio de un panteón (Jelinek, 1969)- género al que se refriere regularmente en su obra posterior. Su pasión por cuentos de horror la compartía no sólo con Peter Handke, sino también con muchos autores del grupo vienés y también con autores más jóvenes como Franzobel.

En la obra de Elfriede Jelinek se mezcla el experimento de la lengua con una crítica feroz a la sociedad austriaca de posguerra, lo que significa que en su obra no sólo encontramos cierta relación con la literatura de vanguardia de Peter Handke o H. C. Artmann, quienes quisieron renovar la lengua de literatura o los géneros de literatura después de la Segunda Guerra Mundial, sino que también debe la autora a otro tipo de literatura la cual se puede caracterizar por una profunda crítica social: una nueva generación de autores después de 1945 se siente libre de la culpa del holocausto pero sufre del silencio sobre los crímenes de la dictadura nazi. Una de las primeras novelas austriacas que se ocupa precisamente de criticar a la sociedad austriaca de posguerra es La piel de lobo (1960) de Hans Lebert (1919-1993): con esta novela, que es una "historia de fantasmas y al mismo tiempo una historia de dios" (según Jelinek), empieza la tradición de la novela antipatriota (Antiheimatroman) en Austria, donde se tematiza la falta de la reflexión acerca de los crímenes durante el nacionalsocialismo en Austria, que trata del silencio y de lo estrecho en una sociedad hostil contra la ilustración y el intelecto, simbolizada por una naturaleza muerta y horrorosa, y por personas más muertas que vivas.

Sin las novelas de Hans Lebert y su influencia no tendríamos las obras de Thomas Bernhard (1930-1989), ni tendríamos las obras de Gerhard Roth, de Norbert Gstrein o de Josef Winkler. Thomas Bernhard es un pilar de la corriente antipatriota en la literatura austriaca, y maestro de la exageración que describe en sus obras un país lleno de "enfermos y locos. A dondequiera que mire, sólo veo moribundos, seres a la deriva que miran hacia atrás" (Bernhard, 1991: 158).

La humanidad representada por la sociedad rural de Austria en las novelas de Thomas Bernhard es una humanidad de zombies que sólo espera la muerte: "Cuando el telón se levanta, todo ha terminado. La vida era una escuela, dijo, en la que se aprendía a morir. Millones y millones de alumnos y profesores la poblaban. El mundo era la escuela de la muerte. [...] El único objetivo docente alcanzable, dijo, es la muerte" (ibid.: 158-159).

Elfriede Jelinek se considera una gran admiradora de La piel de lobo de Lebert y también de la obra de Thomas Bernhard: como Lebert y Bernhard,

${ }^{1}$ Monólogo del príncipe Saurau. El título original de Trastorno apareció en 1967: Verstörung. Francfort del Main: Insel. 
Elfriede Jelinek describe la sociedad de posguerra como "una sociedad llena de muertos vivientes"2 que no se pueden liberar de la historia y la culpa de las crueldades del nazismo, porque no reflejan sus crímenes: "La historia está muerta y enterrada, y al mismo tiempo es lo más vivo. No nos podemos liberar de ella, por mucho que esté enterrada". 3

Al comienzo del siglo XX el motivo de la muerte y el tema de la crítica de la sociedad todavia se pueden ver divididos. Mientras que en la obra de Hugo von Hofmannsthal la muerte es omnipresente, tiene una presencia personal que se convierte en estrella de teatro en la cultura del siglo XX (la muerte en la obra de teatro de Hofmannsthal Cada cual) y la vida no es más que un sueño, el cual nos separa hasta despertar de nuestro estado natural, su gran adversario Karl Kraus criticaba fanáticamente a la sociedad, al imperio habsburgo, que ya no funcionaba porque su lengua ya no funcionaba. La negación del "gnóstico" Hofmannsthal de comunicar (en su Carta del Lord Chandos) es una negación de vivir, la crítica de la lengua del "materialista" Karl Kraus (en su revista $L a$ Antorcha) es una crítica a la sociedad para mostrar de una manera analítica anomalías y su fin. ${ }^{4}$

Después de la Segunda Guerra Mundial y con el trauma del holocausto encontramos los dos topos, la expresión de la irrealidad de la existencia y la crítica racionalista a una sociedad, unidos en las obras austriacas. Por un lado ya en La piel del lobo de Hans Lebert y después en su Círculo del fuego (1971) encontramos una crítica explicita al nacionalsocialismo y al olvido posterior a 1945 de los crímenes de una parte de la población austriaca durante la dictadura nazi. Mientras por otro lado encontramos también en su obra una devaluación gnóstica del mundo y del cuerpo por la cual nos parece el nazismo sólo una posible emanación de la maldad y es así como pierde su unicidad histórica. ${ }^{5}$

En la novela Los hijos de los muertos (1997) de Elfriede Jelinek, Austria aparece como un lugar mortífero, un infierno, una sociedad de zombies, donde la ilustración fracasa en un entorno de tradición y religiosidad. Contra la descripción de Austria como país de muertos protestaron círculos conservadores y el partido de la derecha FPÖ (Freiheitliche Partei Österreichs-Partido Liberal

${ }^{2}$ Entrevista con Elfriede Jelinek en el diario Der Standard, el 10 de octubre de 2004.

${ }^{3}$ Idem.

${ }^{4}$ En Los últimos días de la humanidad de Karl Kraus, él mismo juega con el topos de la muerte de una sociedad, pero de una manera muy analítica. Véase respecto de la relación Kraus-Jelinek también Burckhard Meyer-Sickendiek. 2004. Apokalyptisch vs. postapokalyptisch: Die L̈berwindung der modernen Satire, en: Trans (www.inst.at), Nr.15.

${ }^{5}$ Sobre la discusión de cómo interpretar la obra de Lebert, véase Gerhard Fuchs y Günther A. Höfler, 1998. 
de Austria) - Jelinek aumentaba desde este año sus esfuerzos por criticar al nacionalismo del líder del FPÖ Jörg Haider. Los hijos de los muertos expresa la irrealidad de la realidad política austriaca en la forma de una novela gótica de terror. Otra vez la única solución en esa sociedad sin valores es un nihilismo que también es la patria de los escritores contemporáneos, una nostalgia por un más allá: "Es demasiado pesado caminar alrededor de la nada que hemos construido, ¡mejor nos vamos adentro! A esa luz también agradecemos los autores nuestro ser poco agradable, es un ser imaginado, porque sería horrible tener que ser personas una vez". ${ }^{6}$

En su novela Los excluidos Elfriede Jelinek nos muestra a unos jóvenes que entran en esa nada del nihilismo, que ya no quieren ser personas en esta sociedad, porque sus padres y la sociedad no les pueden dar valores para desarrollar su personalidad. El antihéroe Rainer, hijo de un ex nazi y hombre moralmente podrido, parece sonámbulo que camina hacia una catástrofe después de leer $E l$ absurdo y el suicidio de Camus: "A una distancia mínima Rainer dispara sobre la cabeza de su hermana destrozándole el hueso frontal y sumiéndola, en cuestión de segundos, en la más absoluta inconciencia. [...] Él sabe que ahora tendrá que liquidar a toda su familia para que no haya testigos que puedan denunciarle a la policía" (Jelinek, 1992: 205). ${ }^{7}$

Matando a su familia Rainer se sale de esa sociedad que odia tanto, pero la última frase muestra la negación de comunicar, la negación de participar más en este mundo: "Ahora ya lo saben todo y pueden disponer de mí" (Jelinek, 1992: 208). Los excluidos es la novela más analítica de Elfriede Jelinek, donde quiere, en la tradición de Los sonámbulos de Hermann Broch, mostrar la ausencia de los valores en la sociedad y las consecuencias en los individuos. En vano se buscan utopías en la obra de Jelinek. La esperanza de un cambio en la sociedad simplemente no existe, la vida es un ir al encuentro de la muerte, sobre todo, para la mujer. La boda y el matrimonio son alegorías de la muerte, alegorías que describe Jelinek en su novela Los amantes (1975). Una manera de morir, cuando pensamos en el proyecto Maneras de morir de otra gran escritora austriaca, Ingeborg Bachmann ${ }^{8}$ (1926-1973), puede ser también la sexualidad para una mujer en una sociedad donde la sexualidad está controlada por hombres. En Los

\footnotetext{
6 "Es ist zu mühsam, um das Nichts herumzugehen, das wir geschaffen haben, gehen wir lieber hinein! Diesem Licht verdanken auch wir Dichter unser unangenehmes Wesen, es ist ein gedachtes, denn es wäre furchtbar, müßten wir einmal Persönlichkeiten sein" (Jelinek, 1997: 123). (Trad. del autor.)

${ }^{7}$ El original en alemán de Los excluidos apareció en 1980, Die Ausgesperrten. Hamburgo: Rowohlt.

${ }^{8}$ Jelinek escribió en 1990 el guión para la adaptación al cine de la novela Malina, que es parte del ciclo Maneras de morir de Ingeborg Bachrnann.
} 
amantes Jelinek muestra "que el amor no es algo que viene de Dios o del cielo [...] sino que el amor depende como todo el resto, de hechos económicos". 9

Un personaje que no puede desarrollar una sexualidad normal lo encontramos en la novela La pianista -la obra más personal de Elfriede Jelinek, y tal vez por eso la novela con la cual se hizo famosa en Alemania y Austria en $1983 .{ }^{10} \mathrm{La}$ protagonista Erika Kohut, profesora de piano con casi cuarenta años, todavía vive con su madre en un departamento. La misma Elfriede Jelinek estudiaba desde su adolescencia piano en el Conservatorio de Viena bajo la supervisión de su rígida madre. Su padre murió en 1969 en el manicomio de Viena, Baumgartner Höhe. En La pianista se encuentran ciertos rasgos autobiográficos: "Intenta escabullirse de la madre. [...] Por edad, la madre podría fácilmente ser su abuela. [...] El padre había cedido de inmediato el bastón de mando a la hija y había desaparecido del escenario. [...] Ocasionalmente, Erika va a algún concierto por la noche, pero lo hace cada vez menos. Se pasa el tiempo sentada frente al piano y se revuelve en su carrera pianística abandonada definitivamente hace ya mucho tiempo..." (Jelinek, 1993: 8-11)."

La única salida de Erika del sistema de vigilancia que la madre impone es la automutilación con navajas de rasurar: "La cuchilla está destinada a Su carne. Esta planchita delgada, elegante, de acero azulado, flexible, elástica. Se sienta con las piernas abiertas frente al espejo de aumento que se usa para el afeitado y realiza un corte que agranda la apertura que constituye la puerta al interior de su cuerpo" (ibid.: 89).

Erika no sólo quiso ejercer la venganza contra su cuerpo sino también contra un joven y guapo estudiante de música que la seduce. Pero otra vez Erika se convierte en la víctima — en una víctima que se encuentra más y más en el poder sexual violento del hombre. Y así una vez más le queda su propio cuerpo:

No aparece ningún individuo bondadoso, aunque lo busque. [...] Nadie la apoya con la mano, nadie la ayuda a cargar su peso. Mira débilmente por encima del hombro hacia atrás. ¡El cuchillo ha de llegarle hasta el corazón! Le flaquean las fuerzas que necesitaria, su mirada se pierde y, sin un impulso de enojo o de ira o de pasión, Erika Kohut se hiere en un punto del hombro y comienza a sangrar. La herida no es grave, pero no debe entrarle suciedad ni infectarse. El mundo, que no está herido, no se detiene (ibid.: 22-283).

\footnotetext{
${ }^{9}$ Programa de la puesta en escena de Raststätte, 1994, Wien, Akademietheater, p. 175.

${ }^{10} \mathrm{Y}$ por la premiada adaptación del director austriaco Michael Haneke al cine también, sobre todo en Francia.

${ }^{11}$ El título en original apareció en 1983, Die Klavierspielerin. Hamburgo: Rowohlt.
} 
En La pianista como en Los excluidos se encuentran los polos adyacentes de víctimas y culpables - y muestran que esas categorías cambian con las circunstancias, y que las víctimas de ayer se pueden convertir en los culpables de hoy, así como los niños de ayer se convierten en los padres de hoy. Otra pareja en la obra de Jelinek es la de los deseos y las aversiones.

Que los deseos y las aversiones sean los impulsos para nuestras acciones, con esa teoría de Freud, que usa como motivo principal Jelinek en su novela Deseo (1989) (Jelinek, 2004), ${ }^{12}$ regresamos otra vez al comienzo del siglo XX de la cultura austriaca. Deseo es un contraproyecto contra La historia del ojo de Georges Bataille: escribir una novela pornográfica desde el punto de vista de las mujeres. Es un texto que quiere convertir a la mujer de objeto a sujeto de la pornografia. Pero como la lengua sexual es una lengua construida por hombres, el proyecto de Jelinek se convierte de un libro del deseo en un libro de aversión -y así en una prueba literaria del ensayo de Freud El malestar en la cultura. Jelinek, como Freud, muestran que deseos o pasiones no se pueden imaginar sin aversión, que la aversión es la condición para el deseo. La novela, con el título irónico Deseo y con el lema que aparece en la novela "Nadie aprende a leer sin sufrir", muestra también que la aversión es un impulso para una lectura de manera parcial y para la recepción de la literatura en general. ${ }^{13}$

Con su novela más reciente, Codicia (2000), Jelinek toca todas las teclas de su obra anterior - -hombres que no son más que carne muerta, una sociedad que consta de culpables y víctimas sólo puede crear víctimas y culpables, reticencias a la política austriaca en la actualidad- y otra vez se refiere a Ingeborg Bachmann, ahora deconstruyendo su teoría de las fronteras entre los sexos. Pero el tema central es una vez más la lengua: Jelinek, y aquí regresamos al comienzo de nuestro ensayo, se mete como nunca en contraposición con la tradición de la crítica de la lengua de Hofmannsthal y de Kraus: La yo-narradora no tiene la capacidad de contar la historia, y le da simplemente igual: "Vamos a enterarlo o no, depende si me puedo expresar de una manera entendible o no, y si no me confundo con las personas" (Jelinek, 2000: 17). ${ }^{14}$ Todavía la realidad se muestra demasiado irreal para una lengua que se ahoga en chistes. A pesar de los problemas la yo-narradora sigue narrando, cosa que no hubiera hecho Hofmannsthal. Y tampoco vale la pena cuidar la lengua para mejorar la sociedad (Karl Kraus) - la sociedad ya está perdida: "Pongo toda mi vida, que ya está muerta, en esa zona de agua muerta, pero más muerto que muerto

12 El título en original apareció en 1989: Lust. Hamburgo: Rowohlt.

${ }^{13}$ Véase Thomas Lanz. 1996. "Über die Lust und Unlust am Text, Zu Elfriede Jelineks Lust", Methoden in der Diskussion. Freiburger literaturpsychologische Gespräche: 195-210.

${ }^{14}$ Trad. del autor. 
ya no funciona" (ibid.: 135). Con su última novela no sólo deconstruye los grandes ídolos de la literatura austriaca sino también niega su demanda de una descripción de la sociedad - todo se hunde en un lago de galimatías y frases imposibles de leer fluidamente-, hasta el subtítulo guía al lector al abismo: novela de entretenimiento.

La obra de Elfriede Jelinek no sólo abarca novelas, sino también incluye obras de teatro, Ein Sportstück (Pieza de deporte), Raststätte — sie machen es alle (Estacionarse- todos lo hacen), Totenauberg (Montaña de Totenau) que se convirtieron, por sus puestas en escena en los teatros más importantes en Alemania y Austria, en parte de la cultura en lengua alemana. Desde antes del premio, Elfriede Jelinek era una de las voces literarias más importantes de Europa que representa la cultura de la modernidad occidental. Ella escribió una prolongación (Lo qué pasó después que Nora dejó a su marido, 1979) de una obra de teatro de importancia crucial para el teatro europeo: Nora o la casa de muñecas de Henrik Ibsen. Jelinek tradujo varios textos del inglés y del francés al alemán, entre ellos una de las novelas más elaboradas de la prosa en el siglo XX: Gravity's Rainbow de Thomas Pynchon (Die Enden der Parabel).

Pero no sólo por eso la decisión de Estocolmo es lógica también hay un aspecto político. Con la ampliación de la Unión Europea 2004 hacía el este, Austria, este país pequeño con una tradición tan grande, se encuentra otra vez en la mitad de Europa. Elfriede Jelinek no es una autora que representa una Austria oficial pero sí una autora austriaca que representa la gran tradición literaria austriaca, sobre todo después de la Segunda Guerra Mundial, que se atreve a tomar posición - contra el nacionalismo y contra políticos que todavía no se pueden separar de teorías de antaño-en su obra literaria o como persona privada. Y el nacionalismo es la amenaza más grande del proyecto de una Europa unida. También en ese sentido el Premio Nobel de literatura 2004 para Elfriede Jelinek no debiera ser tan inesperado.

\section{Obras consultadas}

BERNHARD, Thomas. 1991. Trastorno. Madrid: Alfaguara.

FuCHS, Gerhard y Günther A. HöFLER. Ed. 1998. Hans Lebert. Graz, Wien:

Droschl.

JELINEK, Elfriede. 2000. Gier. Hamburgo: Rowohlt. . 1997. Die Kinder der Toten. Hamburgo: Rowohlt. . 1989. Lust. Hamburgo: Rowohlt. (2004. Deseo. Barcelona: Destino.) . 1983. Die Klavierspielerin. Hamburgo: Rowohlt. (1993. La pianista.

Trad. Pablo DiEnER OJEDA. Madrid: Mondadori.) 
1980. Die Ausgesperrten. Hamburgo: Rowohlt. (1992. Los excluidos.

Trad. C. VAZZUEZ DE CASTRO. Madrid: Mondadori.) . 1975. Die Liebhaberinnen. Hamburgo: Rowohlt. 1970. Wir sind lockvögel, baby. Hamburgo: Rowohlt.

. 1969. "Der fremde! störenfriede der ruhe eines sommerabends der ruhe eines friedhofs". Der gewöhnliche Schrecken. Salzburgo: Residenz.

LANZ, Thomas. 1996. "Über die Lust und Unlust am Text. Zu Elfriede Jelineks Lust". Methoden in der Diskussion. Freiburger literaturpsychologische Gespräche, t. 15. Ed. J. CREMERIUS. Würzburg: Königshausen \& Neumann.

LEBERT, Hans. 1993. La piel del lobo. Madrid: Muchnik.

PYNCHON, Thomas. 1976. Die Enden der Parabel. Hamburgo: Rowohlt. 